\title{
Rates of breastfeeding and exposure to socio-economic adversity amongst children with intellectual disability
}

\author{
Nick Gore ${ }^{\mathrm{a}, *}$, Eric Emerson ${ }^{\mathrm{b}, \mathrm{c}}$, Serena Brady ${ }^{\mathrm{a}}$

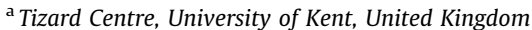 \\ ${ }^{\mathrm{b}}$ University of Sydney, Australia \\ ${ }^{\mathrm{c}}$ University of Lancaster, United Kingdom
}

\section{A R T I C L E I N F O}

\section{Article history:}

Received 7 October 2014

Received in revised form 19 December 2014

Accepted 19 December 2014

Available online

\section{Keywords:}

Intellectual disability

Breastfeeding

Socio-economic

\begin{abstract}
A B S T R A C T
Children with intellectual disability are at increased risk of experiencing poor health relative to their typically developing peers. Previous research indicates that exposure to socio-economic disadvantage contributes towards this disparity but that additional factors (including parenting practices) may be involved in mediating/moderating pathways. This study examined duration of breastfeeding amongst children with and without intellectual disability by a secondary analysis of data from the UK Millennium Cohort Study. Children with intellectual disability were significantly less likely to have been ever breastfed; breastfed exclusively or at all at 3 months or breastfed at all at 6 months relative to children without intellectual disability. None of these differences remained significant when other psycho-social risk factors for reduced breastfeeding were controlled for. The study adds to both the sparse literature on breastfeeding practices amongst families of children with intellectual disability and research demonstrating relationships between socio-economic disadvantage and wellbeing for children with intellectual disability.
\end{abstract}

(c) 2015 Published by Elsevier Ltd.

\section{Introduction}

From early childhood and throughout the life course, people with intellectual disabilities experience poorer health and wellbeing relative to people without disabilities (Anderson et al., 2013; Emerson \& Hatton, 2014; Haveman et al., 2010; NHS Health Scotland, 2004; Oeseburg, Dijkstra, Groothoff, Reijneveld, \& Jansen, 2011; Ouellette-Kuntz, 2005). While part of this disparity relates to well established biological determinants of intellectual disability, exposure to childhood adversities (material or psychological hazards in early life) that are known risk factors for poorer physical and mental health in the general population (Marmot, 2005; Miller, Chen, \& Parker, 2011; World Health Organization, 2008) appear to also play a role.

Indeed, it is known that children with mild to moderate intellectual disabilities (Emerson, 2012a, 2012b; Maulik, Mascarenhas, Mathers, Dua, \& Saxena, 2011) and (to a lesser degree) children with severe to profound disabilities (Chapman, Scott, \& Stanton-Chapman, 2008; Emerson, 2012a) are more likely than their non-disabled peers to be raised by a family of low socio-economic position and, as a consequence, be exposed to a range of environmental adversities associated with this (Emerson, 2013). They are also more likely than their non-disabled peers to be excluded from mainstream education and their local community and to face other adversities and negative life events such as exposure to violence and peer

\footnotetext{
* Corresponding author. Tel.: +44 1227827755 .

E-mail address: n.j.gore@kent.ac.uk (N. Gore).
} 
victimization (Department for Children Schools \& Families, 2008; Department for Education, 2010; Hatton \& Emerson, 2004; Sullivan \& Knutson, 2000).

While relatively few studies have directly examined relationships between childhood adversity, health and wellbeing amongst people with intellectual disability, those that have (Emerson \& Einfeld, 2010; Emerson \& Hatton, 2007a, 2007b; Emerson, Einfeld, \& Stancliffe, 2011; Emerson et al., 2014) suggest 20-50\% of poorer physical and mental health outcomes for children with intellectual disabilities relative to their non-disabled peers can be accounted for by increased risk of exposure to socio-economic disadvantage alone. However, relatively little is known about the pathways that mediate the apparent link between exposure to socio-economic disadvantage and poorer health in children with intellectual disability.

Research in the general population, has increasingly focused on identifying the biological and psycho-social pathways that may mediate or moderate the link between exposure to socio-economic disadvantage and health (Emerson, 2013). One psycho-social pathway that appears particularly relevant to early development is the impact that exposure to socioeconomic disadvantage may have on parenting behaviours and practices (Conger \& Donnellan, 2007; Shonkoff, 2010; Shonkoff, Boyce, \& McEwen, 2009). Other research has attempted to identify the range of protective factors that determine an individual's resilience (their potential to cope with or limit the negative influence of adverse experiences) (Luthar \& Brown, 2007; Mohaupt, 2009; Rutten et al., 2013). To date however, little is known about exposure to variables that may influence resilience or support positive health and wellbeing outcomes among children within intellectual disability and further research in this area has been encouraged (Emerson, 2013; Emerson \& Brigham, 2014).

The current study investigated breastfeeding in early childhood as one possible aspect of parenting that may partially mediate the link between exposure to socio-economic disadvantage and health amongst people with intellectual disabilities. Breastfeeding is a potentially important variable to consider since it is both amenable to intervention and has been associated with a range of benefits in the general population (Hetnzer, Razza, Malone, \& Brooks-Gunn, 2009; Horta \& Victora, 2013a, 2013b; Kaspiris, Griva, Zaphiropulou, Vasiliadis, \& Sawidou, 2010; Kramer \& Kakuma, 2004; Kramer et al., 2008). Specifically, research in this area has suggested that whether or not a child has ever been breastfed and total duration of time during which they were breastfed is negatively associated with risk of early childhood diarrhoea and respiratory tract infection (Horta \& Victora, 2013b) and in later life the risk of obesity and diabetes (Horta \& Victora, 2013a). Positive associations have also been reported between breastfeeding and the health and wellbeing of mothers (Gwinn, Lee, Rhodes, Layde, \& Rubin, 1990; Hahn-Holbrook, Haselton, Schetter, \& Glynn, 2013) and between breastfeeding, cognitive and motor development of children (Horta \& Victora, 2013a; Quigley et al., 2012; Sacker, Quigley, \& Kelly, 2006), though findings in this area are more variable (Holme, MacArthur, \& Lancashire, 2009; Tozzi et al., 2012).

In light of this evidence, the World Health Organization recommends that all children should be exclusively breastfed for the first 6 months of life and should continue to receive breast milk in combination with other foods until 2 years old (World Health Organization, 2001) and the National Institute for Health and Clinical Excellence provides clear recommendations to support mothers to breastfeed in the postnatal period (Dyson et al., 2006; National Institute of Health \& Clinical Excellence, 2006). A variety of factors are however known to reduce the likelihood of breastfeeding initiation and limit total breastfeeding duration (Dennis \& McQueen, 2009; Hamlyn, Brooker, Oleinikova, \& Wands, 2002; Kelly \& Watt, 2005; Thailor \& Mercer, 2009). These include socio-economic factors that as discussed may often reflect the circumstances of families who are raising a child with intellectual disabilities. The current study therefore compared the extent to which a cohort of children with intellectual disabilities were breastfed (both in terms of whether they were ever breastfed and duration of breastfeeding) relative to their non-disabled peers and the socio-economic factors that were associated with this.

\section{Method}

The study is based on secondary analysis of the first four waves of data collected by the UK's Millennium Cohort Study (MCS). MCS data are managed by the Centre for Longitudinal Studies at the University of London and are available to researchers registered with the Economic and Social Data Service (www.esds.ac.uk) through its data archive (www. data-archive.ac.uk). Full details of the design of MCS are available in a series of reports and technical papers (Hansen, 2012; Hansen, Jones, Joshi, \& Budge, 2010; Johnson, 2009, 2012; Jones \& Ketende, 2010; Plewis, 2007; Plewis \& Ketende, 2006), key aspects of which are summarized below.

\subsection{Sampling}

Participant families were randomly selected from Child Benefit Records, a non means-tested welfare benefit available to all UK children at the time the cohort was established. Sampling was geographically clustered to include all four countries of the UK (England, Wales, Scotland, Northern Ireland), and disproportionately stratified to over-sample children from ethnic minority groups and disadvantaged communities (Plewis, 2007). Children and families were drawn from 398 randomly selected electoral wards in the UK. The first survey (MCS1) took place when children were 9 months old and included a total of 18,552 families. Children were followed up at ages three (MCS2; 15,590 families, 84\% retention rate from MCS1), five (MCS3; 15,246 families, 82\% retention rate from MCS1) and seven (MCS4; 13,857 families, 75\% retention rate from MCS1). For each family, information was collected on the target child falling within the designated birth date window. For multiple births (e.g., twins, triplets) information was collected on all children. To avoid the statistical problems associated with the 
clustering of multiple births within households, the present analyses are restricted to one randomly selected target child in multiple birth households.

\subsection{Child disability status}

\subsubsection{Intellectual disability}

Child cognitive ability was assessed at age three using the Bracken School Readiness Assessment (Bracken, 2002) and Naming Subscale of the British Ability Scales (BAS) (Elliott, Smith, \& McCulloch, 1997), selected subscales of the BAS at ages five and seven, and the NFER Progress in Maths test at age seven (Hansen, 2012). For ages five and seven we extracted the first component ('g') from a principle component analysis of all age-standardized subscale/test scores. The first component accounted for $63 \%$ of score variance at age seven and $55 \%$ of score variance at age five. We identified children as having intellectual disability if they scored two or more standard deviations below the mean on the first principle component at age seven ( $n=419$ [3.3\%] of 12,820 children for whom test results were available).

Interviewers did not administer the assessments if the child 'has a learning disability/serious behavioural problem (e.g., severe ADHD, autism) which prevents them from carrying out the assessments', 'is unable to respond in the required manner for each assessment, e.g., reading, writing, manipulating objects', 'is not able to speak or understand English (or Welsh if applicable)' or if consent and co-operation were not forthcoming. If cognitive test scores were missing at age seven, we identified children as having intellectual disability if they scored two or more standard deviations below the mean on the first principal component at age five ( $n=146$ [6.5\%] of 2250 children). If cognitive test scores were missing at age five and at age seven, we identified children as having intellectual disability if they scored two or more standard deviations below the mean on the Bracken School Readiness Assessment at age three ( $n=49$ [4.4\%] of 1105 children). If Bracken scores were not available, we identified children as having intellectual disability if they scored two or more standard deviations below the mean on the BAS Naming Subscale at age three ( $n=54$ [7.6\%] of 711 children). This process allowed us to classify intellectual disability on the basis of cognitive test scores for $99.1 \%$ of children participating at age seven (MCS4).

For 125 children no cognitive test results were available at any age. Cognitive testing was not administered for a variety of reasons including lack of parental consent, failure to co-operate with testing and severity of child disability. For these children we identified intellectual disability on the basis of parental report at age seven. A child was identified as having intellectual disability if both of the following two criteria were met: (1) the child was reported to be receiving special education due to their 'learning difficulty' (the term used in educational services in the UK to refer to intellectual disability); (2) the child was reported to have 'great difficulty' in all three areas of reading, writing and maths. This led to the identification of another 11 children as having intellectual disability.

This procedure led to the identification of 647 of the 18,495 (3.5\%) children participating at Wave 1 where the child's mother was the primary informant as having intellectual disability. Boys were significantly more likely than girls to be identified as having intellectual disability (4.3\% vs 2.6\%; OR =1.67, 95\% CI 1.42-1.96). Given the distribution of test scores (and of intelligence itself) very few of the children identified as having intellectual disability will have had severe intellectual disability. For example, using estimates of the prevalence of severe intellectual disability suggests that MCS is likely to contain approximately 50 children with severe or profound intellectual disability (Maulik et al., 2011).

\subsection{2. $A S D$}

ASD was identified on the basis of key informant report at age seven (in $96.7 \%$ of cases the child's biological mother) to two questions: (1) ‘Has [name] ever been diagnosed by a doctor as having autism or Asperger’s syndrome?'; (2) ‘Has [name] been identified as having special educational needs? If so, was it for ASD?' An affirmative response to either question led to the child being identified as having ASD $(n=227,1.2 \%)$. The majority of children with ASD (62\%) were identified by positive answers to both questions. Boys were significantly more likely than girls to be identified as having ASD (2.0\% vs $0.4 \%$; $\mathrm{OR}=5.12,95 \%$ CI $3.58-7.30$ ).

\subsection{Measures}

\subsubsection{Breastfeeding}

Five indicators of breastfeeding were available from maternal self-report when the child was aged 9 months: (1) whether the child had ever been breast fed; (2) whether the child was being breast fed at 3 months of age; ( 3 ) whether the child was being breast fed at 6 months of age; (4) whether the child was being exclusively breast fed at 3 months of age (i.e., they had not received any formulae milk, cow's milk, other milk or solid food by that age); (5) whether the child was being exclusively breast fed at 6 months of age.

\subsubsection{Household poverty and neighbourhood deprivation}

Five indicators of household poverty and neighbourhood deprivation were selected from Wave 1 data: (1) income poverty defined as living in a household whose equivalized income was 60\% less than the national median (Emerson, Graham, \& Hatton, 2006); (2) experiencing material hardship defined as not owning three or more material assets from a list of eight (e.g., refrigerator, microwave); (3) living in a 'workless' household (a household in which no adult was in employment for more than $16 \mathrm{~h}$ a week); (4) living in a household that key informants reported to be unable to keep warm; (5) living in a 
neighbourhood within the lowest quintile of scores on the Index of Multiple Deprivation for their country (Emerson et al., 2006; Johnson, 2009).

\subsubsection{Maternal resources}

Three indicators of maternal resources were selected from Wave 1 data: (1) low educational attainment; (2) being a single parent when the child was aged 9 months (low educational attainment was defined as having a highest educational qualification less than a General Certificate of Secondary Education at Grade 'C'; Department for Education, 2013); and (3) being employed when the child was aged 9 months.

\subsubsection{Maternal health and wellbeing}

Four indicators of poorer maternal health and wellbeing were collected at Wave 1: (1) possible mental health problem defined as scoring positive on four or more of an abbreviated nine item version of the Malaise Scale developed by the MCS research team (within sample internal consistency =0.73) (Rutter, Tizard, \& Whitmore, 1970); (2) reporting having 'fair' or 'poor' health to an item about overall general health status or reporting having a limiting long-standing illness; (3) maternal obesity; and (4) maternal self-report of being a current smoker.

\subsection{Approach to analysis}

To address missing data (item non-response) for the risk factors, multiple imputation was employed in IBM SPSS 20. This involved the imputation of five parallel data sets. The results presented are pooled estimates from separate analyses run on the five data sets. All analyses were undertaken using sample weights to correct for the oversampling of specific populations and the effects of unit non-response bias in recruitment.

\subsection{Ethical approval}

Ethical approval for the MCS1 was granted by the South-West Multi-Centre Research Ethics Committee (England), and by the London Multi-Centre Research Ethics Committee for MCS2-4. The current study is a secondary analysis of MCS data, and the ethical responsibilities of the present authors included the protection of participants' anonymity and confidentiality.

\section{Results}

\subsection{Prevalence of breastfeeding}

The prevalence of breast feeding of children with and without intellectual disability is presented in Table 1 . As can be seen, on four of the five indicators children with intellectual disability were significantly less likely to be breast fed than their peers. The effect sizes for these differences were small (ever breast fed) or moderate (breast fed at 3 months, exclusively breast fed at 3 months, breast fed at 6 months) (Olivier \& Bell, 2013).

\subsection{Factors associated with breastfeeding}

The associations between child characteristics, household poverty and neighbourhood deprivation, maternal resources and maternal health \& wellbeing and breast feeding of children with intellectual disability are presented in Table 2 . Given the low prevalence of exclusive breast feeding at age 6 months, associations with this indicator are not reported.

As can be seen, there were statistically significant associations between at least one indicator of breast feeding and: (1) four of the five indicators of household poverty and neighbourhood deprivation (income poverty, hardship, workless household, neighbourhood deprivation); (2) two of the three indicators of maternal resources (low education, single parent household); and (3) one of the four indicators of maternal health (current smoker). There were no statistically significant associations between any indicator of breast feeding and either child gender or ASD status.

Table 1

Prevalence of breast feeding by child disability status.

\begin{tabular}{lll}
\hline Indicator & $\begin{array}{l}\text { Typically developing } \\
\text { children (weighted } \\
n=17,965)\end{array}$ & $\begin{array}{l}\text { Children with } \\
\text { intellectual disability } \\
\text { (weighted } n=539)\end{array}$ \\
\hline Ever breast fed & $71.1 \%$ & $57.9 \%$ \\
Breast fed at 3 months & $39.1 \%$ & $24.3 \%$ \\
Exclusively breast fed at 3 months & $25.7 \%$ & $15.6 \%$ \\
Breast fed at 6 months & $23.8 \%$ & $14.3 \%$ \\
axclusively breast fed at 6 months & $0.7 \%$ & $1.1 \%$ \\
\hline
\end{tabular}

*** $p<0.001$. 
Table 2

Associations (odds ratio with 95\% confidence intervals) between child characteristics, household poverty and neighbourhood deprivation, maternal resources and maternal health \& wellbeing and breast feeding of children with intellectual disability.

\begin{tabular}{|c|c|c|c|c|}
\hline Indicator & Ever breast fed & $\begin{array}{l}\text { Breast fed at } \\
3 \text { months }\end{array}$ & $\begin{array}{l}\text { Exclusively breast } \\
\text { fed at } 3 \text { months }\end{array}$ & $\begin{array}{l}\text { Breast fed at } \\
6 \text { months }\end{array}$ \\
\hline \multicolumn{5}{|l|}{ Child characteristics } \\
\hline Male & $1.17(0.75-1.82)$ & $1.11(0.65-1.88)$ & $1.08(0.57-2.06)$ & $0.94(0.49-1.79)$ \\
\hline ASD & $2.10(0.84-5.23)$ & $1.97(0.80-4.84)$ & $0.96(0.27-3.35)$ & $0.93(0.27-3.26)$ \\
\hline \multicolumn{5}{|c|}{ Household poverty and neighbourhood deprivation } \\
\hline Income poverty & $0.50^{* *}(0.32-0.77)$ & $0.50^{* *}(0.30-0.83)$ & $0.67(0.36-1.23)$ & $0.47^{*}(0.25-0.88)$ \\
\hline Material hardship & $0.37^{* * *}(0.22-0.62)$ & $0.55^{*}(0.32-0.95)$ & $0.70(0.36-1.36)$ & $0.52^{*}(0.27-0.99)$ \\
\hline Workless household & $0.54^{* *}(0.35-0.84)$ & $0.72(0.42-1.22)$ & $0.93(0.50-1.75)$ & $0.65(0.34-1.25)$ \\
\hline Unable to keep warm & $1.04(0.45-2.39)$ & $0.48(0.14-1.66)$ & $0.91(0.26-3.16)$ & $0.55(0.13-2.41)$ \\
\hline Deprived neighbourhood & $0.49^{* *}(0.32-0.75)$ & $0.70(0.42-1.18)$ & $0.54(0.28-1.04)$ & $0.58(0.31-1.11)$ \\
\hline \multicolumn{5}{|l|}{ Maternal resources } \\
\hline Low education & $0.58^{*}(0.37-0.88)$ & $0.51^{*}(0.31-0.86)$ & $0.70(0.38-1.30)$ & $0.55(0.30-1.02)$ \\
\hline Single parent & $0.41^{* * * *}(0.25-0.66)$ & $0.59(0.31-1.09)$ & $0.80(0.39-1.64)$ & $0.42^{*}(0.18-0.96)$ \\
\hline Working mother & $1.21(0.74-1.97)$ & $0.79(0.44-1.45)$ & $0.66(0.31-1.43)$ & $0.86(0.42-1.76)$ \\
\hline \multicolumn{5}{|l|}{ Maternal health \& wellbeing } \\
\hline Possible mental health problem & $0.79(0.50-1.23)$ & $1.01(0.60-1.72)$ & $1.32(0.70-2.47)$ & $0.92(0.49-1.76)$ \\
\hline Poor health & $1.20(0.74-1.95)$ & $1.19(0.68-2.09)$ & $1.76(0.91-3.38)$ & $1.07(0.54-2.13)$ \\
\hline Obese & $0.95(0.51-1.77)$ & $0.97(0.46-2.06)$ & $0.57(0.20-1.68)$ & $1.14(0.48-2.72)$ \\
\hline Current smoker & $0.43^{* * * *}(0.28-0.66)$ & $0.30^{* * * *}(0.17-0.52)$ & $0.49^{*}(0.26-0.95)$ & $0.22^{* * * *}(0.10-0.48)$ \\
\hline
\end{tabular}

$* p<0.05$.

** $p<0.01$.

*** $p<0.001$.

There were also statistically significant associations between: (1) at least one indicator of breast feeding and each of the above seven indicators among children without intellectual disability (data available from authors); and (2) child intellectual disability status and exposure to these risk factors for reduced probability of breastfeeding (Table 3 ). All the between-group differences are of moderate or large magnitude.

\subsection{Adjusted risk of breastfeeding}

Given the significant between-group differences in exposure to factors associated with reduced probability of breastfeeding, multivariate logistic regression was used to estimate the risk of reduced rates of breastfeeding associated with intellectual disability while controlling for between-group exposures to the factors associated with reduced risk of breastfeeding listed in Table 3. The adjusted risk (odds ratio) for breastfeeding associated with intellectual disability was: $0.92(0.75-1.13)$ for ever being breastfed; $0.80(0.63-1.01)$ for being breastfed at 3 months; 0.79 (0.60-1.04) for being exclusively breastfed at 3 months; and 0.85 (0.64-1.12) for being breastfed at 6 months. While risk for being breastfed at 3 months, 6 months and exclusively at 3 months were equivalent to small effect sizes, none of the adjusted risk estimates were statistically significant at the conventional level of $p<0.05$.

Table 3

Exposure of children with and without intellectual disability at age 9 months to environmental risk factors associated with lower rates of breastfeeding.

\begin{tabular}{|c|c|c|c|}
\hline Indicator & $\begin{array}{l}\text { Children with } \\
\text { intellectual } \\
\text { disability }\end{array}$ & $\begin{array}{l}\text { Children without } \\
\text { intellectual disability }\end{array}$ & $\begin{array}{l}\text { Risk (odds ratio with } \\
95 \% \text { confidence intervals) } \\
\text { and statistical significance }\end{array}$ \\
\hline \multicolumn{4}{|c|}{ Household poverty and neighbourhood deprivation } \\
\hline Income poverty & $57.6 \%$ & $28.8 \%$ & $3.37^{* * *}(2.72-4.19)$ \\
\hline Material hardship & $74.4 \%$ & $49.8 \%$ & $2.92^{* * *}(2.29-3.73)$ \\
\hline Workless household & $39.8 \%$ & $16.6 \%$ & $3.32^{* * *}(2.67-4.14)$ \\
\hline Deprived neighbourhood & $44.4 \%$ & $21.7 \%$ & $2.88^{* * *}(2.32-3.58)$ \\
\hline \multicolumn{4}{|l|}{ Maternal resources } \\
\hline Low education & $53.9 \%$ & $25.2 \%$ & $3.46^{* * *}(2.79-4.29)$ \\
\hline Single parent & $27.1 \%$ & $14.1 \%$ & $2.27^{* * *}(1.78-2.89)$ \\
\hline \multicolumn{4}{|l|}{ Maternal health \& wellbeing } \\
\hline Current smoker & $46.4 \%$ & $29.2 \%$ & $2.14^{* * *}(1.73-2.66)$ \\
\hline
\end{tabular}

*** $p<0.001$ 


\section{Discussion}

The results of this study indicate that: (1) children with intellectual disability were significantly less likely than their peers to be ever breast fed, breastfed at 3 months, exclusively breastfed at 3 months and breastfed at 6 months; (2) they were also significantly more likely than their peers to be exposed to environmental conditions associated with lower rates of breastfeeding (income poverty, family hardship, no adult in the family working, neighbourhood deprivation, low education, single parent household and mother being a current smoker); (3) adjusting for these between-group differences in exposure to these environmental risk factors reduced the risk of children with intellectual disability not being breastfed to statistical insignificance for all indicators of breastfeeding.

These results add to the existing literature in two important ways. First, they add to the sparse literature on breastfeeding of children with intellectual disability. While a number of studies, have investigated associations between breastfeeding and children's cognitive development (Horta \& Victora, 2013a; Quigley et al., 2012) there have been very few that have focused specifically on breastfeeding amongst children with intellectual or neurodevelopmental disability. Those studies that do exist include an early study that interviewed 29 mothers of children with Down Syndrome (Aumonier \& Cunningham, 1983). Mothers in the study were generally reported to be motivated and able to establish breastfeeding and their child's disability was not found to fundamentally impede this. An alternative finding was reported in a study that compared breastfeeding rates in Dakota amongst a group of children with pervasive developmental delay and a group with intellectual disability only (Burd et al., 1988). In both cases rates of breastfeeding were significantly lower than the national average. This study did not however control for other known risk factors associated with low rates of breastfeeding.

By drawing on a large data set the current study provides more robust evidence that children with intellectual disability are at risk of not being breastfed (or breastfed for reduced durations relative to their peers). The study highlights however that this difference arises in the context of greater exposure to factors associated with reduced breastfeeding more widely and not as a direct consequence of the child's disability. The study therefore provides a further demonstration of heightened socio-economic disadvantage amongst families of children with intellectual disability and adds to emerging literature concerning the impact of such disadvantage on parenting practices (Conger \& Donnellan, 2007; Shonkoff, 2010; Totsika, Hastings, Vagenas, \& Emerson, 2014). Since breastfeeding has been recognized as a protective factor for a range of health conditions in early and later development (Hetnzer et al., 2009; Horta \& Victora, 2013a, 2013b; Kaspiris et al., 2010; Kramer \& Kakuma, 2004; Kramer et al., 2008), it is possible that breastfeeding duration serves as one of the mediating pathways through which the less advantageous social circumstances faced by children with intellectual disability leads to poorer health. Further research in this area is therefore warranted.

\section{Strengths and limitations}

The main strengths of the present study are: (1) the use of a population-based sample of children with and without intellectual disability and ASD and (2) the measurement of multiple indicators of environmental adversity (Emerson, 2013).

However, as in all studies, there were limitations that impact the interpretation of these findings. First, while having access to a large, longitudinal data set is an asset, data sets (such as the MCS) that are designed for multiple purposes commonly utilize abbreviated forms of measures or constructs. For example, the MCS used abbreviated scales of cognitive functioning rather than complete IQ tests.

Second, while the overall sample was relatively large, it was of insufficient size to examine the extent to which our results generalized to children with severe intellectual disability. We estimate, for example, that the available sample of 11,776 children at age three would have contained less than 40 children with severe or profound intellectual disability (Maulik et al., 2011).

Third, there are clear limitations associated with sole reliance on self-report data, especially when applied to factors that may be subject to significant social desirability biases (e.g., parenting practices). Unfortunately, the MCS does not contain observational measures of parenting that could be used to evaluate the validity of self-report data.

\section{Future research}

Future research needs to build on the strengths and address the limitations of the present study. Particularly important is the need for future research to: (1) further investigate the possible mediation role of breastfeeding for development, wellbeing and health of children with intellectual disability; (2) identify further key parenting practices and other factors that serve as protective factors or support resilience for the wellbeing of children with intellectual disability; (3) examine the experiences of families of children with intellectual disability in relation to breastfeeding and the availability and quality of breastfeeding support for these families.

\section{References}

Anderson, L. L., Humphries, K., McDermott, S., Marks, B., Sisarak, J., \& Larson, S. (2013). The state of the science of health and wellness for adults with intellectual and developmental disabilities. Intellectual E' Developmental Disabilities, 51, 385-398.

Aumonier, M. E., \& Cunningham, C. C. (1983). Breast feeding in infants with Down's syndrome. Child: Care, Health and Development, 9, 247-255.

Bracken, B. A. (2002). Bracken school readiness assessment. London: Harcourt Assessment. 
Burd, L., Fisher, W., Kerbeshian, J., Veslely, B., Durgin, B., \& Reep, P. (1988). A comparison of breastfeeding rates among children with pervasive developmental disorder and controls. Journal of Developmental and Behavioural Paediatrics, 9, 247-251.

Chapman, D., Scott, K., \& Stanton-Chapman, T. (2008). Public health approach to the study of mental retardation. American Journal of Mental Retardation, 113(2), $102-116$.

Conger, R. D., \& Donnellan, M. B. (2007). An interactionist perspective on the socioeconomic context of human development. Annual Review of Psychology, 58, 175 199.

Dennis, C. L., \& McQueen, K. (2009). The relationship between infant-feeding outcomes and postpartum depression: A qualitative systematic review. Paediatrics, $123,736-751$.

Department for Children Schools and Families (2008). Bullying involving children with special educational needs and disabilities. London: Department for Children Schools and Families.

Department for Education (2010). Children with special educational needs 2010: An analysis. London: Department for Education.

Department for Education (2013). GCSE and equivalent attainment by pupil characteristics in England, 2012/13. London: Department for Education.

Dyson, L., Renfrew, M., McFadden, A., McCormick, F., Herbert, G., \& Thomas, J. (2006). Promotion of breastfeeding initiation and duration: Evidence into practice briefing. London: National Institute for Health and Clinical Excellence.

Elliott, C., Smith, P., \& McCulloch, K. (1997). British ability scales (2nd ed.). London: nferNelson.

Emerson, E. (2012a). Household deprivation, neighbourhood deprivation, ethnicity and the prevalence of intellectual and developmental disabilities. Journal of Epidemiology and Community Health, 66, 218-224.

Emerson, E. (2012b). Understanding disabled childhoods: What can we learn from population-based studies? Children E Society, 26, 214-222.

Emerson, E. (2013). Commentary: Childhood exposure to environmental adversity and the well-being of people with intellectual disabilities. Journal of Intellectual Disability Research, 57, 589-600.

Emerson, E., Blacher, J., Einfeld, S., Hatton, C., Robertson, J., \& Stancliffe, R. (2014). Environmental risk factors associated with the persistence of conduct difficulties in children with and without intellectual disabilities or autistic spectrum disorders. Research in Developmental Disabilities, 35, 3508-3517.

Emerson, E., \& Brigham, P. (2014). Exposure of children with developmental delay to social determinants of poor health: Cross sectional study. Child: Care Health Development. http://dx.doi.org/10.1111/cch.12144

Emerson, E., \& Einfeld, S. (2010). Emotional and behavioural difficulties in young children with and without developmental delay: A bi-national perspective. Journal of Child Psychology and Psychiatry, 51, 583-593.

Emerson, E., Einfeld, S., \& Stancliffe, R. J. (2011). Predictors of the persistence of conduct difficulties in children with cognitive delay. Journal of Child Psychology and Psychiatry and Allied Disciplines, 52, 1184-1194.

Emerson, E., Graham, H., \& Hatton, C. (2006). The measurement of poverty and socio-economic position in research involving people with intellectual disability. In L. M. Glidden (Ed.), International review of research in mental retardation (pp. 77-108). New York: Academic Press.

Emerson, E., \& Hatton, C. (2007a). The contribution of socio-economic position to the health inequalities faced by children and adolescents with intellectual disabilities in Britain. American Journal of Mental Retardation, 112, 140-150.

Emerson, E., \& Hatton, C. (2007b). Poverty, socio-economic position, social capital and the health of children and adolescents with intellectual disabilities in Britain: A replication. Journal of Intellectual Disability Research, 51, 866-874.

Emerson, E., \& Hatton, C. (2014). Health inequalities and people with intellectual disabilities. Cambridge: Cambridge University Press.

Gwinn, M. L., Lee, N. C., Rhodes, R. H., Layde, P. M., \& Rubin, G. L. (1990). Pregnancy, breastfeeding and oral contraceptive and the risk of epithelial cancer. Journal of Clinical Epidemiology, 43, 559-568.

Hahn-Holbrook, J., Haselton, M. G., Schetter, C. D., \& Glynn, L. M. (2013). Does breastfeeding offer protection against maternal depressive symptomology? A prospective study from pregnancy to 2 years after birth. Archives of Women's Mental Health, 16, 411-422.

Hamlyn, B., Brooker, S., Oleinikova, K., \& Wands, S. (2002). Infant feeding 2000. London: The Stationery Office.

Hansen, K. (Ed.). (2012). Millennium cohort study: First, second, third and fourth surveys. A guide to the datasets (7th ed.). London: Centre for Longitudinal Studies, Institute of Education, University of London.

Hansen, K., Jones, E., Joshi, H., \& Budge, D. (Eds.). (2010). Millennium cohort study fourth survey: A user's guide to initial findings (2nd ed.). London: Centre for Longitudinal Studies, Institute of Education, University of London.

Hatton, C., \& Emerson, E. (2004). The relationship between life events and psychopathology amongst children with intellectual disabilities. Journal of Applied Research in Intellectual Disabilities, 17(2), 109-118.

Haveman, M., Heller, T., Lee, L., Maaskant, M., Shooshtari, S., \& Strydom, A. (2010). Major health risks in aging persons with intellectual disabilities: An overview of recent studies. Journal of Policy and Practice in Intellectual Disabilities, 7, 59-69.

Hetnzer, N. M. P., Razza, R. A., Malone, L. M., \& Brooks-Gunn, J. (2009). Associations among feeding behaviors during infancy and child illness at two years. Maternal E Child Health Journal, 13, 795-805

Holme, A., MacArthur, C., \& Lancashire, R. (2009). The effects of breastfeeding on cognitive and neurological development of children at 9 years. Child: Care, Health E Development, 34, 583-590.

Horta, B. L., \& Victora, C. G. (2013a). Long-term effects of breastfeeding: A systematic review. Geneva: World Health Organization.

Horta, B. L., \& Victora, C. G. (2013b). Short-term effects of breastfeeding: A systematic review on the benefits of breastfeeding on diarrhoea and pneumonia mortality. Geneva: World Health Organization.

Johnson, J. (Ed.). (2009). Millennium cohort study: Geographic identifiers in MCS. London: Centre for Longitudinal Studies, Institute of Education, University of London.

Johnson, J. (Ed.). (2012). Millennium cohort study: Psychological, developmental and health inventories. London: Centre for Longitudinal Studies, Institute of Education, University of London.

Jones, E., \& Ketende, S. (Eds.). (2010). Millennium cohort study: User guide to analysing MCS data using SPSS. London: Centre for Longitudinal Studies, Institute of Education, University of London.

Kaspiris, A., Griva, T., Zaphiropulou, C., Vasiliadis, E., \& Sawidou, O. (2010). The necessity of breastfeeding for the prevention of bone and joint diseases during childhood. International Journal of Child Health and Human Development, 3, 33-40.

Kelly, Y., \& Watt, R. (2005). Breastfeeding initiation and exclusive duration at 6 months by social class: Results from the Millennium Cohort Study. Public Health Nutrition, 8, 417-421.

Kramer, M. S., Aboud, F., Mironova, E., Vanilovich, I., Platt, R. W., \& Matush, L. (2008). Breastfeeding and child cognitive development: New evidence from a large randomized trial. Archives of General Psychiatry, 65(5), 578-584.

Kramer, M. S., \& Kakuma, R. (2004). The optimal duration of exclusive breastfeeding: A systematic review. Advances in Experimental Medical Biology, 554 63-77.

Luthar, S. S., \& Brown, P. J. (2007). Maximizing resilience through diverse levels of inquiry: Prevailing paradigms, possibilities, and priorities for the future Development and Psychopathology, 19, 931-955.

Marmot, M. (2005). Social determinants of health inequalities. Lancet, 365, 1099-1104.

Maulik, P. K., Mascarenhas, M. N., Mathers, C. D., Dua, T., \& Saxena, S. (2011). Prevalence of intellectual disability: A meta-analysis of population-based studies. Research in Developmental Disabilities, 32, 419-436.

Miller, G., Chen, E., \& Parker, K. (2011). Psychological stress in childhood and susceptibility to the chronic diseases of aging: Moving toward a model of behaviora and biological mechanisms. Psychological Bulletin, 137, 959-997.

Mohaupt, S. (2009). Resilience and social exclusion. Social Policy \& Society, 8, 63-71.

National Institute of Health and Clinical Excellence (2006). Routine postnatal care of women and their babies. London: National Institute of Health and Clinica Excellence.

NHS Health Scotland (2004). People with learning disabilities in Scotland: Health needs assessment report. Glasgow: NHS Health Scotland. 
Oeseburg, B., Dijkstra, G. J., Groothoff, J. W., Reijneveld, S. A., \& Jansen, D. E. M. C. (2011). Prevalence of chronic health conditions in children with intellectual disability: A systematic literature review. Intellectual E' Developmental Disabilities, 49, 59-85.

Olivier, J., \& Bell, M. L. (2013). Effect sizes for $2 \times 2$ contingency tables. PLOS ONE, 8, e58777.

Ouellette-Kuntz, H. (2005). Understanding health disparities and inequities faced by individuals with intellectual disabilities. Journal of Applied Research in Intellectual Disabilities, 18, 113-121.

Plewis, I. (2007). The millennium cohort study: Technical report on sampling (4th ed.). London: Centre For Longitudinal Studies.

Plewis, I., \& Ketende, S. (2006). Millennium cohort study: Technical report on response. London: Centre for Longitudinal Studies, Institute of Education, University of London.

Quigley, M. A., Hockley, C., Carson, C., Kelly, Y., Renfrew, M. J., \& Sacker, A. (2012). Breastfeeding is associated with improved child cognitive development: A population-based cohort study. Journal of Paediatrics, 160, 25-32.

Rutten, B. P. F., Hammels, C., Geschwind, N., Menne-Lothmann, C., Pishva, E., \& Schruers, K. (2013). Resilience in mental health: Linking psychological and neurobiological perspectives. Acta Psychiatrica Scandinavica, 128, 3-20.

Rutter, M., Tizard, J., \& Whitmore, K. (1970). Education, health and behaviour. London: Longman.

Sacker, A., Quigley, M. A., \& Kelly, Y. J. (2006). Breastfeeding and developmental delay: Findings from the millennium cohort study. Paediatrics, 118, 682-689.

Shonkoff, J. P. (2010). Building a new biodevelopmental framework to guide the future of early childhood policy. Child Development, 81, $357-367$.

Shonkoff, J. P., Boyce, W. T., \& McEwen, B. S. (2009). Neuroscience, molecular biology, and the childhood roots of health disparities: Building a new framework for health promotion and disease prevention. Journal of the American Medical Association, 301, 2252-2259.

Sullivan, P. M., \& Knutson, J. F. (2000). Maltreatment and disabilities: A population-based epidemiological study. Child Abuse E Neglect, 24, 1257-1273.

Thailor, D., \& Mercer, J. (2009). Variables associated with breastfeeding duration. Journal of Obstetric, Gynaecologic, E Neonatal Nursing, $38,259-268$.

Totsika, V., Hastings, R. P., Vagenas, D., \& Emerson, E. (2014). Parenting and the behaviour problems of young children with an intellectual disability: Concurrent and longitudinal relationships in a population-based study. American Journal of Intellectual and Developmental Disabilities, $119,422-435$.

Tozzi, A. E., Bisiacchi, P., Tarantino, V., Chiarotti, F., D’elia, L., \& De Mei, B. (2012). Effect of duration of breastfeeding on neuropsychological development at 10 to 12 years of age in a cohort of healthy children. Developmental Medicine E Child Neurology, 54, 843-848.

World Health Organization (2001). Global strategy for infant and young child feeding. The optimal duration of exclusive breastfeeding. Geneva: World Health Organization.

World Health Organization (2008). Closing the gap in a generation: Health equity through action on the social determinants of health. Final report of the Commission on the Social Determinants of Health. Geneva: World Health Organization. 